\title{
An Examination of the Completion Rate of Masters Programs at Makerere University Business School
}

\author{
Samuel Eyangu1, Vincent Bagire², Moses Kibrai ${ }^{3}$ \\ ${ }^{1}$ Department of Accounting, Makerere University Business School, Kampala, Uganda \\ ${ }^{2}$ Department of Business Administration, Makerere University Business School, Kampala, Uganda \\ ${ }^{3}$ Graduate Research Center, Makerere University Business School, Kampala, Uganda \\ Email: bagirev@yahoo.com
}

Received 10 September 2014; revised 8 October 2014; accepted 22 October 2014

Copyright (C) 2014 by authors and Scientific Research Publishing Inc.

This work is licensed under the Creative Commons Attribution International License (CC BY).

http://creativecommons.org/licenses/by/4.0/

c) (i) Open Access

\section{Abstract}

This study was carried out to examine the completion rate for masters' degree programs at Makerere University Business School. We investigated the delay in research, teaching schedules, administrative processes and students' own challenges as possible limitations. The study relied on opinion from former students on possible strategies which can be put in place to improve completion. The study examined the masters of Business Administration (MBA) and the Msc. Accounting and Finance (Ms.AF). The study was cross sectional and used both qualitative and quantitative data. A sample size of 211 students was used covering those who had completed their masters within a two-year period and those who were not able to complete in the same period. Findings revealed that the completion rate of masters program was still very low. Delay in returning the research comments both by external examiners and the Graduate and Research Centre office was found to be the major cause, among others. This finding had support in the literature. The study recommends to management to improve the research and teaching environment.

\section{Keywords}

Master of Business Administration, Master of Accounting and Finance, Graduate Study, Research, Teaching, Business School, MBA Completion, Higher Degrees, Uganda

\section{Background}

Programme completion and timely graduation have become increasingly important policy issues for many universities and governments (Murphy \& Welch, 1993). Graduation rate is one of the aspects that measure institu-

How to cite this paper: Eyangu, S., Bagire, V., \& Kibrai, M. (2014). An Examination of the Completion Rate of Masters Programs at Makerere University Business School. Creative Education, 5, 1913-1920. 
tion's effectiveness (Hebel, 1999). Students' completion rate is the ratio of the total number of students successfully completing in the last year of their programme in a given year to the total number of students of official graduation in the population (World Bank, 2004). Not completing a programme on time increases the cost of doing it due to the hidden costs which are always incurred by both the students and the university. For instance, students are charged extension fees, while university's resources like libraries and research supervisors become overused due to the backlog of students who must be cleared to be able to graduate (Makerere University Higher Degrees joining instructions, 2004; Tetty, 2010). However, for one to complete a master's program on time, there is need for him/her to manage research activities properly. The motivation of this study was to examine the completion rates at Makerere University Business School following anecdotal evidences that many students were delaying on their master's programs. We needed to draw empirical conclusions on the phenomena.

Many stakeholders have attached delay in completion of postgraduate courses to the research course unit as it influences one's ability to complete the program. In many cases, however, students and university management do not give it much attention. Makerere University Business School (MUBS) was established in 1997 by Makerere University (MUK) Establishment of Constituent Colleges' Order, with the mandate of offering business and management education to its clients, undertaking research and overseeing the Uganda Colleges of Commerce (UCCs). By 2009, there have been twelve masters' programmes run by MUBS, of which MBA (Master of Business Administration) and MsAF (Master of Science in Accounting and Finance) degrees are the pioneer programs. The MBA constitutes the greatest number of students (Makerere University Business School Annual Report, 2004/05). The Graduate and Research Centre (GRC) is the Faculty in MUBS which is responsible for overseeing the graduate programs of the school through teaching, research and publications (Makerere University Business School Strategic Plan, 2008/09). Ensuring timely completion of graduate students is one of the objectives of GRC. In line with the above GRC objective, at the $128^{\text {th }}$ meeting of the Senate of Makerere University held in May 2007, the guidelines for Masters programs were reviewed. It was agreed that masters students should complete their programmes in two years time. This was re-echoed in the $89^{\text {th }}$ GRC Higher Degrees Committee meeting which agreed that masters students should be engaged in series of research seminars at the beginning of Semester II of every academic year to enable them to appreciate the key research concepts as well as the new graduate research policy (Minutes of the $89^{\text {th }}$ School Higher Degrees Committee, 2008).

MBA as a professional management degree programme admits students from differing academic backgrounds including business, management, sciences, arts, and humanities; whereas MsAF admits students from strictly a business and management background. Anecdotal evidence indicates that students without prior experience in research face more challenges in adoption to research and require extra effort to cope with the research demands. Although most students complete their course work on time, they take longer than expected to graduate because of not completing their research projects (Makerere University Business School, 2003, Minutes of the $79^{\text {th }}$ and $80^{\text {th }}$ Management committee). MUBS in a bid to improve the completion rate of masters students came up with strategies like increase in the number of research supervisors for masters' programmes, conducting series of research seminars for both postgraduate students and research supervisors, training of research supervisors, creation of research sub-committees to quicken the proposal review process and availing research guidelines to students (Minutes of the $89^{\text {th }}$ School Higher Degrees Committee Meeting, 2008, Nassali, 2008). Similarly, in an effort to address the delay and speed the process of completion among postgraduate students, Makerere University introduced plan B type of research in 2001 besides the research dissertation. Plan B adopts a problem solving approach, based on applying/developing appropriate management instruments and is aimed at providing practical solution to an identified organizational problem. The findings should be of practical relevance and value to managers and organizations.

However, despite these efforts aimed at improving timely completion rate of postgraduate students, evidence shown in Table 1 indicates that the completion rate is still low among the postgraduate students. An analysis of the completion rate of the masters students from the Graduate \& Research Centre (GRC) database (2010) shows that on average, students on MBA who complete their programme on time stands at $13.8 \%$, while for MsAF it is even much lower standing at $9.2 \%$. On average masters students take four years to complete it and graduate as against the average of two years prescribed by most universities (Buckley \& Hooley, 1988, Haksever \& Manisali, 2000).

\section{Synthesis of Related Literature}

To develop insights into the problem of completion rate in masters programs we reviewed works of various 
Table 1. Admission and completion rate for two selected programs.

\begin{tabular}{ccccccc}
\hline Programme & \multicolumn{2}{c}{ MBA } & \multicolumn{2}{c}{ Ms.AF } \\
\hline Academic Year (AY) & Admitted & Graduated & Completion rate (\%) & Admitted & Graduated & Completion rate (\%) \\
\hline $2001 / 02$ & 86 & 15 & 17.4 & 38 & 6 & 15.8 \\
$2002 / 03$ & 71 & 13 & 18.3 & 33 & 3 & 9.1 \\
$2003 / 04$ & 126 & 14 & 11.1 & 43 & 5 & 11.6 \\
$2004 / 05$ & 122 & 12 & 9.8 & 67 & 4 & 6.0 \\
$2005 / 06$ & 117 & 16 & 13.7 & 56 & 5 & 8.9 \\
$2006 / 07$ & 128 & 15 & 11.7 & 53 & 7 & 13.2 \\
$2007 / 08$ & 68 & 10 & 14.7 & 46 & 0 & 0 \\
\hline
\end{tabular}

Source: Graduate and Research Centre.

scholars on the subject. There was a limitation of scarce literature from the local environment on masters programs; we benefitted from Wamala et al. (2012) and Wamala \& Oonyu (2012). They studied the extended candidature plus non completion of a $\mathrm{PhD}$ and the completion time dynamics for masters students at Makerere University. They provide rich insights on the local context regarding the current study. Buckley \& Hooley (1988) posited that a report by the Council of graduate schools in the USA gave the median period of a doctoral degree as 7.6 years against the minimum of four, masters degrees at 4 years instead of 2 years prescribed by most universities. Haksever and Manisali (2000) confirmed a similar position in their study of PhD supervision in the UK.

Buttery, Richter, \& Filho (2005) stated that postgraduate education is a fundamental component of University life. However, concern has been increasing in recent years over the proportion of research students who fail to submit a thesis after a period of public or industrial support. One underlying cause cited for poor completion rates is, along with the problems of a personal nature, the documented dissatisfaction by students with the research experience and industry with the research outcome. Ssegawa \& Rwelamila (2009) explained that low completion rate and long completion periods for research-based degrees have received considerable attention from scholars. The lack of hands-on skills in the research process on the part of students especially in the early part stages (research definition and design) and hence the need for a facilitative framework has been cited as the major challenge to research students. Smallwood (2004) emphasized the issue of low completion rate among undergraduates in the US noting that timely completion is a social asset. The deeper root of low completion rates is examined by Lovitts from a personal experience; she left two doctoral programs before finishing a third one, in sociology, at the University of Maryland in 1996 (Lovitts, 1996; Lovitts, 2001 in Gardner 2008). The reasons seem to be diverse and may not be attributed to a single factor. The low completion rate translates into high costs for the sponsors and the institution. Studies in US have further indicated that completion rates varied across the major disciplines, with humanities recording the highest compared to natural sciences (Gardner, 2008). The high completion rate in sciences was attributed to the manner in which students interact and bond as a faculty research community especially through laboratory sessions, as opposed to the research isolation found in humanities.

The reasons for the low completion rate of postgraduate programmes may be grouped into three major themes namely student deficiencies, inappropriate supervision process and inappropriate research environment. Studies have examined factors ranging from personal, academic and financial with no standard finding of which seems to influence completion ahead of the others (Gardener, 2008; Berelson, 1960 in Gardner, 2008; Wamala et al. 2012).

Excellent research depends on the combination of research facilities and a high quality, well-trained research workforce. It is important for Universities to continuously offer trainings to research supervisors and students for quality output to be achieved. The case for supervisor training has been made although not clearly emphasized (Skerritt and Roche, 1994; Anderson \& Freeman, 1977; Hegarty \& Johnston, 2008). Nevertheless some Universities (such as the University of Aalborg and the University of South Australia) have decided upon a compulsory training for all new PhD supervisors by providing duty statements, codes of practice and progress monitoring. Previous studies have noted indicators of supervisor effectiveness and supported independently by other re- 
searchers over the years. For example, the importance of academic standing was highlighted by Moses (1994) and supervisory competence by Skerritt and Roche (1994), ESRC (2001), and Zhao (2003). Supervisor effectiveness is therefore, judged basing on the various indicators of supervisory style, competence, attitude and intellectual standing.

The main challenges in the research process among postgraduate students are articulated by Skerritt and Ryan (1994), as inadequate supervision in terms of experience, commitment, and time, emotional and psychological problems, students' intellectual and social isolation, their insecurity as to standards and lack of confidence in their ability to complete their theses within the specified time. This may lead to communication problems between supervisor and student. The role of the supervisor should therefore be like a super form of teaching and critical conversation (Knowles, 1999) and mentorship (Taylor, 1995). Supervisor motives may incorporate knowledge attainment, joint publications and recognition (self-esteem), each motive carrying different expectations of students (Hockey, 1996).

\section{Methodology}

The study focused on academic years from 2001/02. These were years for which concerns on completion delays scaled up in the public arena. The data that were readily available for our analysis were for a population of 468 students who were admitted in the academic years 2005/06, 2006/07 and 2007/08. The study used a cross sectional design. Two programs were selected namely Master of Business Administration (MBA) and Master of Science in Accounting and Finance (Ms.AF) because they have been run at the Business school for relatively a longer period of time than other programs. A proportionate sample of 211 was drawn using tables generated by Bartlett et al. (2001) comprising 141 MBA and 70 Ms.AF. Primary data was collected using a questionnaire constructed on a five point Likert type scale. The items covered the views on their delays and proposals for improvement. These were developed after reviewing the literature. We used expert validity on the instrument before using it for data collection. 110 usable questionnaires were received back giving a response rate of 52\%. Secondary data was obtained from various records at the Graduate Resource center. Completion rate was based on the measures by Hebel (1999) of completion against enrollment. Analysis techniques were accomplished using SPSS.

\section{Results}

\section{Year of Admission and Year of Completion}

The results in Table 1 below and Figure 1 show the distribution of the respondents in terms of year of admission. Their completion was due within two years of the academic year of their admission respectively.

The results in Table 2 as depicted also in Figure 1 show that majority of the students on MBA and Ms.AF did not complete their program on time. On average, $86.2 \%$ of the MBA students did not complete while Ms.AF over $90.8 \%$ were still on the program after the two year period. Further analysis revealed that on average students took four years to complete their programmes. It is important to note that from records the Ms.AF have one year for class work and there after engage in research in the second year of their enrollment. On the other hand the MBA are engaged in class work for three semesters before beginning the dissertation project. The results indicated that the completion rate dropped sharply from 2001 before rising again in 2005. That of Ms.AF dropped suddenly again to zero while the MBA has maintained some rise.

\section{Views on Challenges Students Face}

The survey enlisted the respondent views on challenges that students face during their study time as affecting their ability to complete the program on time. The highest agreement in the factors was related to lack of proper guidance in research. They faced difficulty in problem identification, literature review and choice of methodology and supervision related reasons. The other challenges included were related to job demands, health, family and funding.

The respondents noted that there are a number of factors that contribute to the low completion rate of masters students in MUBS. The findings show that delay in returning the comments of the research reports by the external examiners is viewed to be the major cause for low completion rate. This is indicated by the mean of 3.97 and 


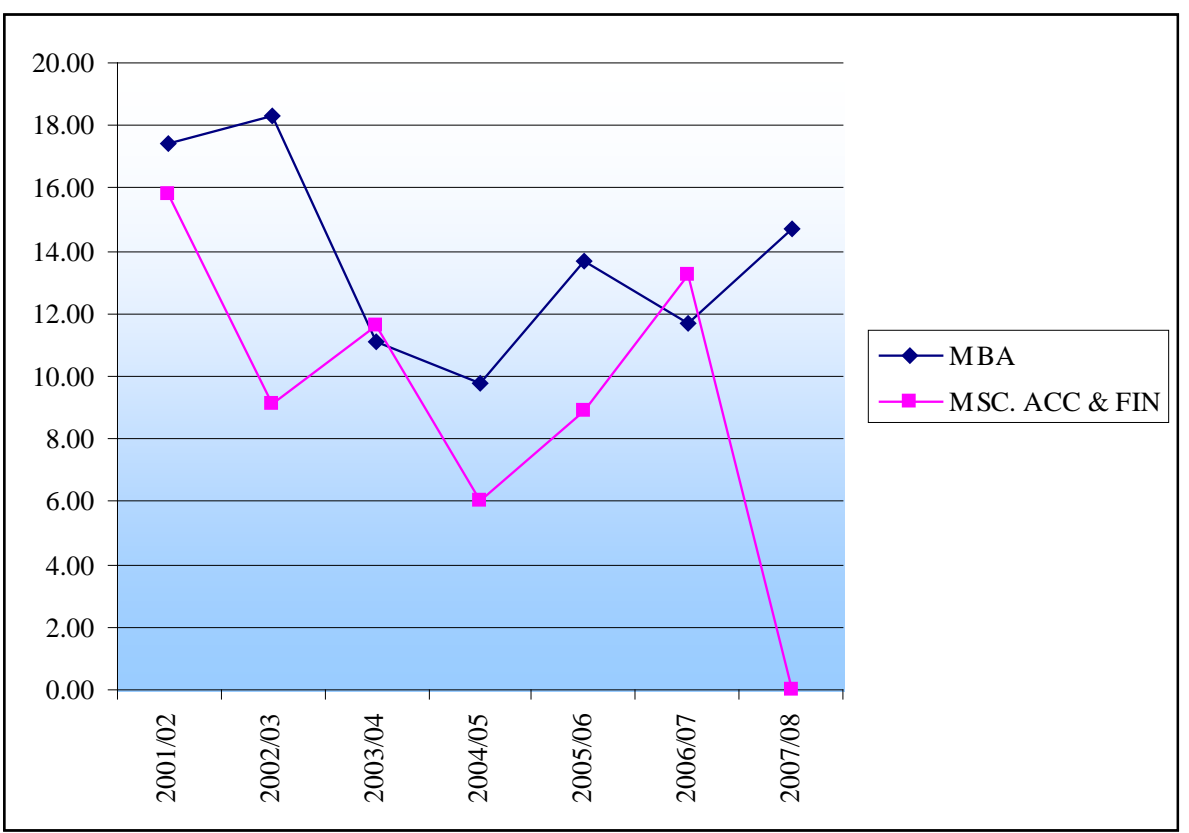

Figure 1. Graphical view of the completion rate for masters programs.

Table 2. Views on why students do not complete their studies on time.

\begin{tabular}{|ll} 
Items rated as reasons for delayed completion & Mean range \\
\hline
\end{tabular}

\section{High incidence}

Delay in returning the comments of the research reports by the external examiners

Personal weakness on the part of the student when it comes to research process

Job workload and related responsibilities

Transfers at work places to up-country stations

$3.80-3.97$

Lack of commitment to research on the part of the students

Slow process of reviewing proposals by supervisors/reviewers

Delay in calling for viva voce meetings

\section{Moderate incidence}

Having two supervisors slows down the research progress

Slow process of giving feedback of the Committee to students

Hectic study schedules during the semester sessions

$3.70-3.75$

Getting better jobs and promotions at work in the course of the masters studies

Low incidence

Family Responsibilities

Relaxed University policies on enforcing completion requirements

Lack of funds on the part of the students

Health related problems

Undependable supervisors

a standard deviation of 0.87 . It implies that delay in returning research comments to students lead to prolonged study period which eventually contribute to high backlog of students failing to complete their programmes on time. The results also show that lack of commitment to research by postgraduate students is a major cause for low completion. The study also revealed that lack of facilities like reliable internet and the study environment not being conducive contribute to low completion rate. The factor of supervisors was also widely mentioned; either not being supportive or where they are two not agreeing easily on the students work. Other factors were in the real domain of the students such as family responsibility, work responsibilities, funding and health, which all contributed to the low completion rate in the selected programs. 


\section{Approaches Adopted by MUBS to Improve Completion Rate}

The study assessed the approaches adopted by the Graduate Resource center in attempt to improve the situation. We sought views of the respondents. The findings are in Table 3.

The table shows the views on the different approaches adopted by MUBS Graduate and Research Centre to improve the completion rate. The study noted that a number of strategies were adopted to try and improve the situation. The major one was introduction of type B research which does not involve academic rigor but is problem based. Those who do plan B research are not examined through the viva voce. Their dissertations are not sent to external examiners, the hitherto known stage contributing to the delays. GRC also started briefing students on the different types of research, subcommittees for plan A and plan B were set up so as to quicken the proposal review process. However, the findings from this study show that, these strategies have not improved the completion rate yet since they had been in place for a short term by the time of this study. For example the mean of 2.54 and standard deviation of 0.92 shows that respondents disagreed with the view that proposals are reviewed quickly. On a positive note, the respondents agreed that previous students' dissertations are available in the library for students doing research dissertations as indicated by a mean of 3.79. Respondents also agreed with the statement that research guidelines (booklets) had been availed to masters' students to facilitate the research process. The views on other approaches still provide strong reservations on how effective they will contribute to improving the situation.

\section{Proposals for Improvement}

The study sought views from the respondents on what more could be done by the school to improve completion

Table 3. Views on why students do not complete their studies on time.

\begin{tabular}{|c|c|c|}
\hline Items & Mean range & SD \\
\hline $\begin{array}{l}\text { Previous students' dissertations have been availed in the library for students doing research. } \\
\text { Research booklets have been availed to students of all the masters programs. } \\
\text { Students have been briefed about type A \& B type of research. }\end{array}$ & 3.79 & 0.98 \\
\hline $\begin{array}{l}\text { Students have been briefed about the penalties for failure to complete masters on time. } \\
\text { Students have been guided about the possible supervisors in their areas of specialization. }\end{array}$ & 3.18 & 1.13 \\
\hline $\begin{array}{l}\text { Seminars are conducted for supervisors to update them of changes in research guidelines. } \\
\text { Relevant research text books are available in the library for students doing research. } \\
\text { Seminars are conducted for students to guide them in research/dissertation writing. }\end{array}$ & 3.02 & 0.89 \\
\hline $\begin{array}{l}\text { Comments are availed to students immediately after the proposal review meetings. } \\
\text { Proposals are reviewed immediately after submission to Graduate and Research Centre. }\end{array}$ & 2.54 & 0.92 \\
\hline
\end{tabular}

Table 4. Suggestions for improving completion rate by MUBS masters students.

\begin{tabular}{|c|c|}
\hline Item & Suggested strategies for improving the completion rate of masters programmes at MUBS \\
\hline Research assessment & $\begin{array}{l}\text { - Increase on the number of external examiners. } \\
\text { - Subcommittees to approve students' proposals should be revitalized. } \\
\text { - } \quad \text { Train students on data analysis packages so as to enable students understand their research work better. } \\
\text { - } \quad \text { Review masters programme structures and merge some course units to create time for research. } \\
\text { - } \quad \text { Supervisor-student ratio be improved to handle the increasing number of masters students. } \\
\text { - Upload all the previous students' research on the database for easy access. } \\
\text { - Up-to-date research books should be availed in the library. } \\
\text { - } \quad \text { Subscribe to the online international journals to access research articles. } \\
\text { - Improve on the internet connectivity, availability and speed. } \\
\text { - Improve on the teaching facilities for masters students. } \\
\text { - Improve on the class room facilities for masters programmes. } \\
\text { - Improve on the institutional structure between Makerere University and Makerere University Business School. }\end{array}$ \\
\hline
\end{tabular}


rates among postgraduate students.

We did not focus on what the students should do in their domain. The results are clustered under key items as in Table 4.

\section{Conclusion and Management Implications}

The findings on completion rate of Masters Program in MUBS have far reaching academic and management implications. The study reveals that in general, completion among postgraduate students is very low. This finding concurs with previous studies of Buckley \& Hooley (1988). The low completion rate is a challenge to MUBS image, graduates status and is straining to both students and the School. This has an implication of over stretching facilities and staff and low spirit to students. The challenges that were identified are manageable although some of them might be financially demanding. On its part, the school should streamline the research process. The available facilities should be appropriately used to enable those students who are keen to complete doing so in time. Strict guidelines will definitely change attitude of candidates who have taken policy laxity to their advantage. The existing staff capacity is capable of handling the workload; they need to be motivated to work within the existing functional facilities. On their part, students should be able to handle the challenges in their realm, like self motivation, family and work related demands. With the increasing computer usage in the country, students should find it easier to search for relevant materials, typeset their work and communicate with supervisors. Lack of relevant research skills is still a problem that should squarely be handled by management. There is no way the school will stand to be counted with academic staff who lack such skills and cannot help masters students. The skills of collecting and interpreting information and using knowledge in all its forms are a priority in a society. This is a profound knowledge base for higher education.

The efforts by the GRC so far have been commendable. There is a need for consistency and follow up. The implication of this holdup is making the students who were very serious with their research relax and lose the momentum. The observation by scholars that excellent research depends on the combination of outstanding research facilities and a high quality, well-trained research workforce is important in our conclusion. It is imperative for MUBS to continuously allocate resources and improve management of research for quality output.

We recommend more analytical studies to assess attitudes of both lecturers and students towards research and examine efficiency in managing the research function. The study may have been limited by methodological factors especially sampling approach.

\section{References}

Anderson, E. F., \& Freeman, A. H. (1977). Graduate School Success of Black Students from White Colleges and Black Colleges. The Journal of Higher Education, 48, 294-303. http://dx.doi.org/10.2307/1978682

Bartlett, J. E., Kotrlik, J. W., \& Higgins, C. C. (2001). Organizational Research: Determining Appropriate Sample Size in Survey Research. Information Technology, Learning, and Performance Journal, 19, 43-50.

Buckley, P. J., \& Hooley, G. J. (1988). The Non-Completion of Doctoral Research in Management: Symptoms, Causes and Cures. Educational Research, 30, 110-120.

Haksever, A. M. and Manisali, E. (2000). Assessing Supervision Requirements of PhD Students: The Case of Construction Management and Engineering in the UK. European Journal of Engineering Education, 25, 19-32.

Buttery, E. A., Richter, E. M., \& Filho, W. L. (2005). An Overview of the Elements That Influence Efficiency in Postgraduate Supervisory Practice Arrangements. International Journal of Educational Management, 19, 7-26.

http://dx.doi.org/10.1108/09513540510574920

ESRC (2001). Training Guidelines 2001, Chief Executive’s Foreword, Economic and Social Research Council, Swindon.

Gardner, S. K. (2008). Student and Faculty Attributions of Attrition in High and Low-Completing Doctoral Programs in the United States. Higher Education, 58, 97-112. http://dx.doi.org/10.1007/s10734-008-9184-7

Hegarty, C., \& Johnston, J. (2008). Graduate Training: Evidence from FUSION Projects in Ireland. Educational Training, 50, 391-405. http://dx.doi.org/10.1108/00400910810889075

Hebel, S. (1999). Virginia Board Wants to Link State Aid to Colleges to Their Performance in Key Areas. The Chronicle of Higher Education, A33, My 281999.

Hockey, J. (1996). Strategies and Tactics in the Supervision of UK Social Science PhD Students. Qualitative Studies in Education, 9, 481-500. http://dx.doi.org/10.1080/0951839960090409

Knowles, S. (1999). Feedback on Writing in Postgraduate Supervision. 
Lovitts, B. E. (1996). Who Is Responsible for Graduate Student Attrition-The Individual or the Institution? Toward an Explanation of the High and Persistent Rate of Attrition. The Annual Meeting of the American Educational Research Association, New York, 8-12 April 1996.

Makerere University Business School (May 2004/2005 and 2007/08). Graduate and Research Centre Strategic Plan.

Makerere University Business School (2003). Minutes of Management Committee Meetings (79th and 80th Management Committee Meetings).

Makerere University Business School (2008). Minutes of the School Higher Degrees Committee Meetings (89th School Higher Degree Committee Meetings.

Makerere University (2004). Higher Degrees and Postgraduate Diploma Joining Instructions. Kampala: School of Postgraduate Studies, 4.

Murphy, K., \& Welch, F. (1993). Inequality and Relative Wages. American Economic Review, 83, 104-109.

Moses, I. (1994). Planning for Quality in Graduate Studies. In O. Zuber-Skerritt, \& Y. Ryan (Eds.), Quality in Postgraduate Education (pp. 3-13). London: Kogan Page.

Nassali, S. (2008). Attitudes towards Research and Intention to Carry out Research: A Case of Postgraduate Students at Makerere University Business School. MBA Dissertation, Kampala-Uganda: Makerere University.

Skerritt, O. Z., \& Roche, V. (1994). A Constructivist Model for Evaluating Postgraduate Supervision: A Case Study. Quality Assurance in Education, 12, 82-93. http://dx.doi.org/10.1108/09684880410536459

Ssegawa, J. K., \& Rwelamila, P. D. (2009). The Research Skill Factor as a Cause for High Postgraduate Attrition Rate. Journal of Engineering, Design and Technology, 7, 293-322. http://dx.doi.org/10.1108/17260530910998703

Zhao, F. (2003). Postgraduate Research Supervision: A Process of Knowledge Management. Quality in Higher Education, 9, 187-197. http://ultibase.rmit.edu.au/Articles/may01/zhao1.htm

Smallwood, S. (2004). Doctor Dropout. The Chronicle of Higher Education, 16 January 2004, 19 A.

Taylor, P. (1995). Postgraduate Education and Open Learning: Anticipating a New Order. The Australian Universities Review, 38, 28-31.

Tetty, W. (2010). Challenges of Developing and Retaining the Next Generation of Academics: Deficit in Academic Staff Capacity at African Universities. Status Report, The Partnership of Higher Education in Africa.

Wamala, R., Ocaya, B., \& Oonyu, J. C. (2012). Extended Candidature and Non-Completion of a Ph.D. at Makerere University, Uganda. Contemporary Issues in Education Research, 5, 174-184.

Wamala, R., \& Oonyu, J. (2012). Completion Time Dynamics for Master's and Doctoral Studies at Makerere University. Contemporary Issues in Education Research (CIER), 5, 131-137.

World Bank Group (2004). Global Data Monitoring Information System. Washington DC: The World Bank Group. 
Scientific Research Publishing (SCIRP) is one of the largest Open Access journal publishers. It is currently publishing more than 200 open access, online, peer-reviewed journals covering a wide range of academic disciplines. SCIRP serves the worldwide academic communities and contributes to the progress and application of science with its publication.

Other selected journals from SCIRP are listed as below. Submit your manuscript to us via either submit@scirp.org or Online Submission Portal.
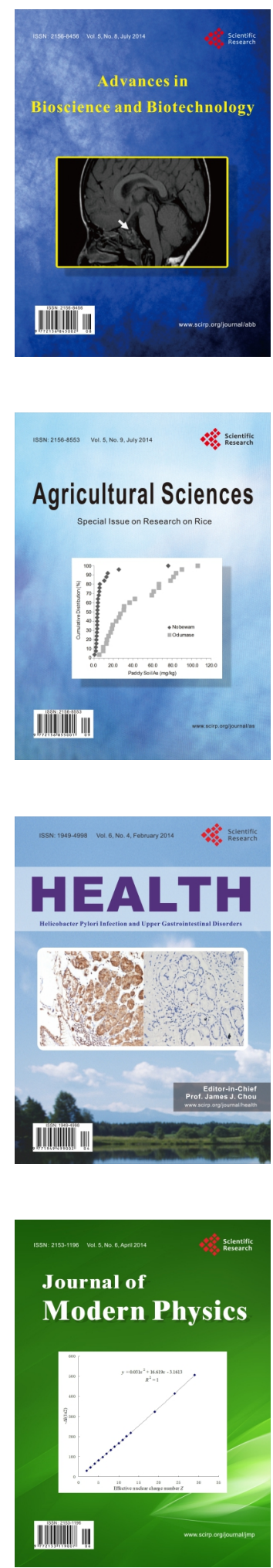
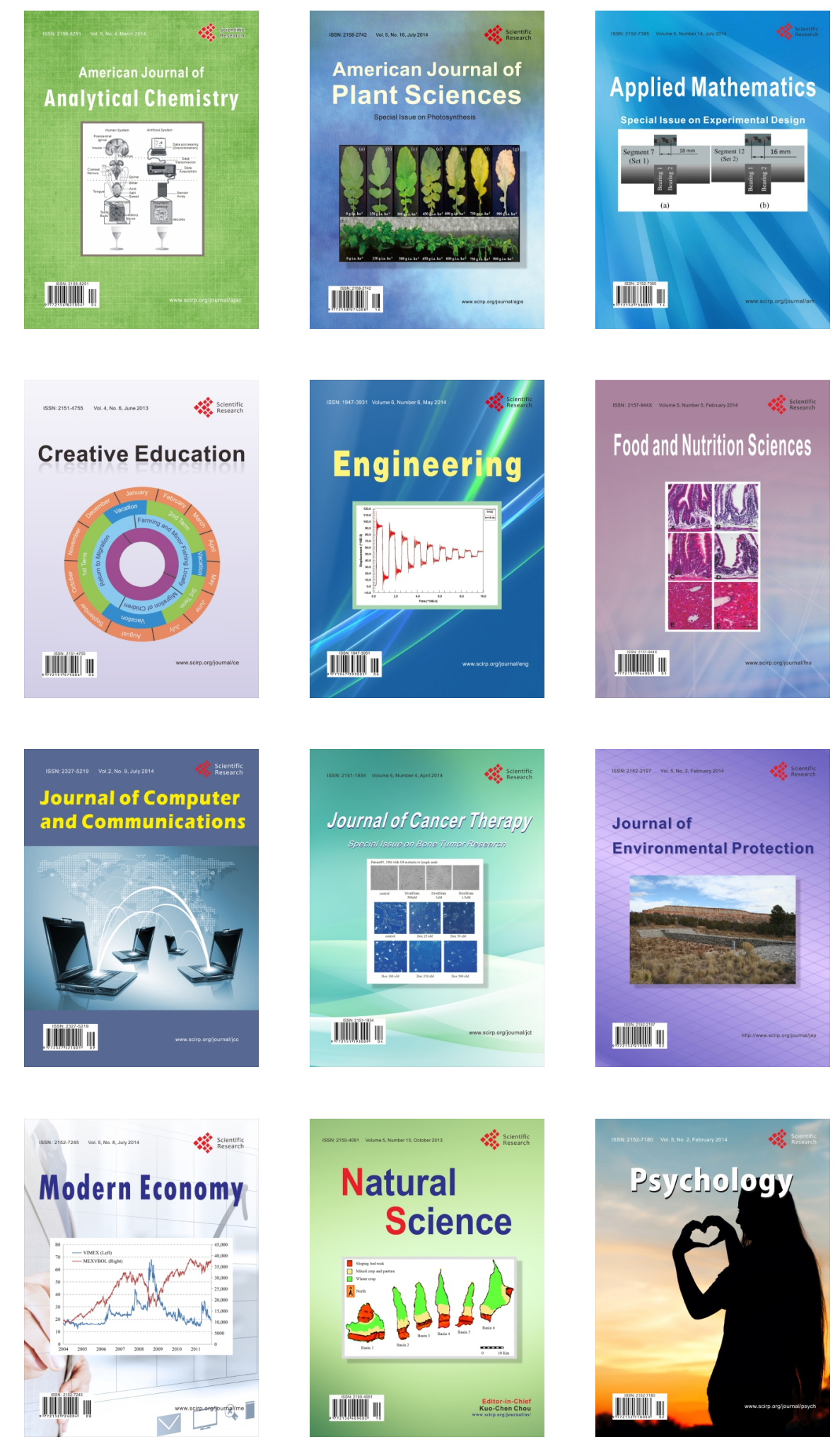